\title{
Intellectual Capital and Business Performance in Professional Football Clubs: Evidence From a Longitudinal Analysis
}

\author{
Federica Ricci, Vincenzo Scafarto, Domenico Celenza, Ida Samantha Gilvari \\ University of Cassino and Southern Lazio, Cassino, Italy
}

\begin{abstract}
This paper aims to explore the impact of intellectual capital efficiency (ICE) on firm performance in the context of professional football clubs. In particular, our aim is twofold: (1) to provide measures of ICE specifically tailored to professional football businesses; and (2) to empirically investigate whether some dimensions of ICE, namely, human capital and relational capital efficiency, are positively associated with sporting performance, here used as a proxy for business performance. This paper develops a quantitative analysis of club-level panel data using the statistical technique known as mixed-effects linear regression for longitudinal analysis. The research spans a time period of five years and specifically the sporting seasons from 2007/2008 up to 2011/2012. The empirical findings of this study provide tentative evidence that ICE, especially as far as relational capital is concerned, is positively associated with on-pitch performance of professional football businesses. On the counterpart, results for the impact of human capital efficiency (HCE) do not consistently come out with the (positive) expected signs. More specifically, our findings suggest that relational capital efficiency, meaning the ability to develop and nurture positive business relationship with relevant external stakeholders, is a significant consideration for football club managers; on the other, they might shed light on the actual business model of professional football clubs that, in our analysis, does not appear consistent with the long-held hypothesis of winning maximization. The main limitation of this study lies in the fact that our indicators do not fully capture all relevant dimensions of the intellectual capital (IC) construct.
\end{abstract}

Keywords: intellectual capital efficiency (ICE), firm performance, professional football clubs

\section{Introduction}

The impact of intellectual capital (IC) on business performance has become a popular research topic, due to a widespread recognition that competitive advantage in present-day economy rests more on intangible and knowledge-based assets a company possesses than on tangible ones.

In the last few decades, management theory has in fact acknowledged that a company's competitiveness is more and more dependent on the strategic management of its intangibles. Several terms and conceptualizations

Federica Ricci, adjunct professor in Business Economics, Department of Economics and Law, University of Cassino and Southern Lazio. Email: federica.ricci@unicas.it.

Vincenzo Scafarto, researcher in Business Economics, Department of Human, Social and Health Sciences, University of Cassino and Southern Lazio.

Domenico Celenza, researcher in Business Economics, Department of Economics and Law, University of Cassino and Southern Lazio.

Ida Samantha Gilvari, Ph.D. student in Business Economics, Department of Economics and Law, University of Cassino and Southern Lazio. 
have been introduced to describe and analyze the role of cognitive and intangible assets, such as invisible assets (Itami \& Roehl, 1987), intangible assets (Hall, 1992; 1993), knowledge assets (Spender \& Grant, 1996), as well as social capital (Nahapiet \& Ghoshal, 1998) and human capital (Hitt, Bierman, Shimizu, \& Kocchar, 2001).

However, scholars have consistently argued that knowledge and intangible resources are the pre-eminent drivers of competitive advantage and superior firm performance. The rationale behind this contention is that cognitive and intangible resources are often rare, valuable, and difficult-to-replicate (Barney, 1991) as opposed to physical or tangible assets, which makes them the main source of competitive advantage and enablers of superior performance.

According to Schiuma, Lerro, and Sanitate (2008), IC has emerged as an "umbrella concept" that has effectively synthesized prior conceptualizations and insights, in an attempt to come up with an operative notion of a company's cognitive and intangible assets. Most well-known and often-cited definitions of IC are as follows: "the sum of everything everybody in your company knows that gives you a competitive edge in your marketplace” (Stewart, 1991, as cited in Sveiby, 1998, p. 1); “the combined intangible assets of market, intellectual property, human-centered and infrastructure which enable the company to function” (Brooking, 1996, p. 12); "the possession of knowledge, applied experience, organizational technology, customer relationships, and professional skills that provide a company with a competitive edge in the market" (Edvinsson, 1997, p. 368); "the sum of hidden assets of the company not fully captured by the balance sheet and thus include both what is in the heads of organizational members ("human capital") and what is left in the company when they leave ("structural capital”)" (G. Roos \& J. Roos, 1997, p. 8); and "the group of knowledge assets that are owned and/or controlled by an organization and most significantly drive organization value creation mechanisms for targeted company key stakeholders” (Schiuma et al., 2008, p. 172).

While these definitions do not fully overlap, they share at least three common features: (1) Intellectual assets are hidden, because they are not normally appearing on the balance sheet; (2) IC is not constrained to knowledge held by individuals but also includes knowledge stored within organizational infrastructures as well as knowledge embedded in marketing relationships (Youndt, Subramaniam, \& Snell, 2004); and (3) Only such knowledge becomes IC that can be transformed into value identifiable on the market, or in other words, into benefits the customer is willing to pay for (Pulic, 2008). This suggests that IC does not include intangibles that have no impact over the firm's future potential and it is assumed that competitive advantage depends on how efficient the firm is in building, sharing, leveraging, and using its knowledge.

If the management of IC lies at the heart of value-creating processes (Bontis, 1998), then the need arises to measure and control a company's intellectual capital efficiency (ICE), that is the actual contribution of its intangibles to value creation, in order to allow managers to better handle this variable (Pulic, 2008; G. Roos \& J. Roos, 1997).

Over the past decade, IC researchers have been striving to provide reliable measures of ICE and test their relationship with business performance. As a result, a surge of writings and empirical studies has accumulated (e.g., Bassi \& Van Buren, 1999; Bontis, Keow, \& Richardson, 2000; Pulic, 2000; Riahi-Belkaoui, 2003; Firer \& Stainbank, 2003; Shiu, 2006; Chan, 2009; Chen, Cheng, \& Hwang, 2005; Sharabati, Jawad, \& Bontis, 2010; Maditinos, Chatzoudes, Tsairidis, \& Theriou, 2011; Alipour, 2012; Zeglat \& Zigan, 2014), but a truly conclusive evidence has not yet been reached as to the impact of IC on firm performance. 
While empirical investigations have been undertaken in a range of industry contexts and particularly in knowledge-intensive industries such as banking (e.g., Cabrita \& Vaz, 2006), financial (e.g., Appuhami, 2007), insurance (e.g., Alipour, 2012), technological (e.g., Shiu, 2006), pharmaceutical (e.g., Sharabati et al., 2010), and hotel industry (e.g., Zeglat \& Zigan, 2014), there appear to be only a few studies empirically testing the impact of ICE on performance within professional football clubs (Mnzava, 2013; Dimitropoulos \& Koumanakos, 2015). Prior research (Shareef \& Davey, 2005) has confined itself to assessing the extent and quality of IC disclosure of annual reports of football clubs. Interestingly, a positive correlation was found between the size of clubs, on-pitch performance, and their overall IC disclosure (as measured by a specially devised index).

This paper aims to help fill this gap by empirically investigating the relationship between ICE and performance in a population of professional football businesses belonging to the top-flight division (Serie A) of Italian football.

Professional football appears an ideal context for IC research for mainly three reasons. Firstly, the business nature of the football sector is "intellectually" or personnel-intensive. Secondly, this dynamic and socially influential industry is unique in recognizing the human capital as investments on the balance sheet, as recommended by IC theorists (e.g., Pulic, 2008). Thirdly, the football sector has gone relatively under-explored by IC researchers.

The remainder of the paper proceeds as follows. Section 2 presents a brief overview of the relevant existing literature regarding the impact of IC on business performance. Section 3 presents the research methodology. Section 4 presents both our empirical analysis and reports, providing a discussion on the main results. Section 5 , concluding the paper, summarizes the main findings, highlights current limitations but, at the same time, outlines possible directions for future research.

\section{Review of Relevant Literature}

In the growing knowledge-based economy, IC has been identified as a major source of sustainable competitive advantage for business organizations. Hitt et al. (2001, p. 13) argued that "intangible resources are more likely than tangible resources to produce a competitive advantage”. Similarly, Teece (2000) pointed out that a firm's superior performance heavily depends on its ability to defend and use the intangible assets it creates.

As the management of intellect is believed to be at the heart of value in the current "knowledge era" of business (G. Roos \& J. Roos, 1997; Bontis, 1998), the notion has been put forth that IC is a critical driver of business performance (Itami, 1987; Nahapiet \& Ghoshal, 1998; McGaughey, 2002). In other words, a positive causal relationship is assumed between IC and business performance (Marr \& Roos, 2005).

Several empirical investigations have been undertaken to assess this contention, covering a range of national and industry contexts. A good deal of this research has reported a positive association between measures of IC and measures of business performance. For instance, Bassi and Van Buren (1999), perhaps the earliest researchers in the field, have found measures of IC investment (e.g., training as a percentage of payroll) to be significantly correlated with measures of performance (e.g., market-to-book value (M/BV)) of US public traded companies. Bontis et al. (2000), by using a psychometrically-validated questionnaire, have investigated the inter-relationships between sub-constructs of IC (namely, human, structural, and relational capital) and business performance across service and non-service industry sectors in the Malaysian business context. Their conclusion is that IC has a meaningful relationship with business performance regardless of the industry type. 
Pulic (2000), the originator of the value added intellectual coefficient (VAIC) method for IC measurement, has found a significant degree of correlation between the (mean) value of IC and the market value of 30 randomly selected companies from the UK FTSE 250; Riahi-Belkaoui (2003) has found a positive association between IC (proxied by the number of trademark applications) and the performance of US-based multinational firms measured by the net value added over total assets; Chen et al. (2005) have reported a positive impact of IC (as measured by VAIC) on financial performance and market value of Taiwanese listed companies; Cabrita and Vaz (2006) have proved that IC is significantly related to organizational performance in the Portuguese banking industry using survey data based on executives' perceptions; Appuhami (2007) has found that IC performance (VAIC) has a significant positive relationship with investors' capital gains on shares in Thai banking, finance, and insurance sector; Sharabati et al. (2010) have found a positive association between perceptual measures of IC and business performance for the entire population of pharmaceutical manufacturers in Jordan; Alipour (2012) has found a significant positive relationship between IC (VAIC) and its components and financial performance (as measured by return on assets (ROA)) of 38 Iran insurance companies; Zeglat and Zigan (2014), using general managers' perception of IC and business performance, have shown all dimensions of IC to have a positive and significant impact on the business performance of Jordanian hotels. Eventually, Dimitropoulos and Koumanakos (2015) have found a positive association between ICE (as measured by VAIC) and measures of profitability (ROA and return on equity (ROE)) for a sample of listed European football clubs.

Other investigations, however, have found only limited and mixed evidence to support the notion that IC favourably impacts firm performance. For instance, Firer and Stainbank (2003) have found a positive relationship between IC and profitability (ROA), a negative relationship with productivity (as measured by asset turnover (ATO)), and no significant relationship with market valuation (M/BV) in South African public traded companies; Shiu (2006) has found a positive correlation of IC with profitability (ROA) and market valuation (M/BV) but a negative correlation with firm productivity (ATO), based on the annual reports of 80 Taiwan listed technology firms; Maditinos et al. (2011), using a panel of 96 Greek companies listed in the Athens Stock Exchange, have only found a significant relationship between human capital efficiency (HCE, as measured in VAIC) and financial performance while failing to prove the positive impact of other IC components; Chan (2009), using all the constituent companies of Hang Seng Index in Hong Kong Stock Exchange, has found an overall lack of association between IC (VAIC) and four financial indicators (ROA, $\mathrm{ROE}, \mathrm{M} / \mathrm{BV}$, and $\mathrm{ATO}$ ), although some IC components were found to explain a substantial variance in business performance.

These inconsistent findings might be due, inter alia, to country-specific or methodological differences; however, they suggest the need for further investigations that evaluate the impact of ICE in different national and industry contexts.

In this study, we investigate the relationship between ICE and performance in the professional football industry, using a population of football clubs playing in the top-tier division (Serie A) of Italian football. Based on prior similar research (Mnzava, 2013; Dimitropoulos \& Koumanakos, 2015), we expect to find a positive association between specific dimensions of ICE and club performance. In a more formal fashion, the research hypotheses are as follows:

H1: There is a positive relationship between human capital efficiency and sporting performance.

H2: There is a positive relationship between relational/structural capital efficiency and sporting performance. 
Where the sporting performance is assumed as a proxy for business performance. The rationale for this methodological choice is detailed below.

\section{Research Methodology}

\section{The Dependent Variable}

In this study, the business performance of football clubs is proxied by their sporting (on-pitch) performance. The rationale for this choice is based on the assumption that on-pitch performance is a primary driver of football club revenues. Empirical evidence for this assumption has been found by Szymanski and Kuypers (1999), Deloitte and Touche (1999; 2000a; 2000b), and Barajas, Fernández-Jardón, and Crolley (2005). These are not, however, the only studies assuming clubs' revenues as a function of sporting performance, both under an explicit exclusive context or in combination with other factors. For instance, El-Hodiri and Quirk (1971) modelled the revenues of a professional sports club as a function of its sporting performance and the size of the local fan base. Furthermore, Hoehn and Szymanski (1999), within the context of an analysis of competitive balance, determined clubs' revenues, along with other factors, from the percentage of wins each club gets.

Based on these insights, we use on-pitch performance as an indirect measure of a club's revenue-generating capability, and then, we investigate its association with some measures of ICE. Specifically, we measure on-pitch performance by the number of competition points gained at the end of each sporting season by our population of football clubs in their domestic league (Serie A). As Barajas et al. (2005) pointed out, this is an appropriate measure of sporting performance, when dealing with open-league competitions. An alternative measure, which is oft-used in US-based studies of (team) sports economics, is the winning percentages, computed as the ratio of games won to the total number of games played during the season. However, the use of winning percentages is not entirely appropriate in open-league competitions, since it excludes drawn outcomes which are considered to constitute a positive outcome and for which teams are awarded league points. As far as specifically the Serie A is concerned, a win is worth three points, a loss is worth none, while if the match ends with a tie result both clubs are awarded one point. At the end of the season, after 38 rounds of matches, the team with the higher score (obtained by the sum of gathered points) is declared winner of the league.

In open-league competitions, it is also possible to measure sporting performance by ranking clubs on the basis of their end-of-season league placing. This is, for instance, the approach used by Szymanski and Smith (1997) and Szymanski and Kuypers (1999). However, for studies adopting a season-by-season analysis of club performance, it appears methodologically more appropriate to use measures based on match outcomes (cf. Dawson, Dobson, \& Gerrard, 2000). In this study, we adopt as a measure of sporting performance the number of league points gained divided by the maximum achievable points. This variable is named after as relative score (RelSCORE). As an illustrative example, if Juventus F.C. in the season 2007-2008 has a final record of 70 points, its RelSCORE is obtained by dividing this number by 114 which is the maximum achievable (as each club plays 38 matches and is awarded 2 points per win). This way, the number of end-of-season points is expressed as a proportion of the maximum possible (other papers using this measure of club performance include, for instance, Dawson et al., 2000). Taking the RelSCORE as the dependent variable, we express it as a function of ICE of football clubs as measured by specially devised indicators. 


\section{Conceptual Framework and Constructs of the Study}

The conceptual framework for this study is rooted in the mainstream IC literature (e.g., Edvinsson, 1997; Edvinsson \& Malone, 1997; Pulic, 2000) which subdivides the high-order construct of IC into two main components: human capital and structural capital.

As far as human capital is concerned, IC theorists acknowledge that the concept is by no means a new one. Adam Smith (as cited in Burton-Jones \& Spender, 2011, p. 2) in the Wealth of Nations (1776) wrote of an individual's acquisition of talents as "a capital fixed and realized as it were, in his person”. Likewise, Schultz (1961, p. 2) pointed out that it has been "long known that people are an important part of the wealth of nations".

In the IC literature, human capital is defined as "the combined knowledge, skill, innovativeness, and ability of the company's individual employees to meet the task at hand” (Bontis, 2001, p. 45). It is assumed to be the foundation of IC as everything in the current market environment relies on the individual's ideas, knowledge, and skills. In particular, human capital is especially important to organizations in so far it serves as a source of innovation and strategic renewal (Edvinsson, 2000; Stewart, 1997; Brooking, 1996).

In the setting of professional football, a highly human-intensive industry (Shareef \& Davey, 2005), the major constituents of human capital are the players', the management's, and the supporting staff's present and potential skills (Andrikopoulos \& Kaimenakis, 2009).

The second main dimension of IC is structural capital. It encompasses all knowledge stored in organizational infrastructures (e.g., databases, organizational procedures, patents, trademarks) and "everything else of organizational capability that supports those employees' productivity - in other words everything that gets left behind at the office when employees go home” (Bontis, 2001, p. 45). Within structural capital, one major component left behind when employees go home is relational capital, also referred to as "customer capital” (Edvinsson, 1997), that is the relationships developed with key customers (Bontis, 2001). Edvinsson and Malone (1997) defined customer capital as the strength and loyalty of customer relations. It is the most difficult of the IC sub-components to develop since it is the most external to the organization's core.

In the setting of professional football, the relational capital of a football club appears to be most dependent on its relationships with supporters, broadcast media (most notably, television networks), and sponsors, which represent the main drivers of revenues in this industry context.

Based on this basic taxonomy of IC, we regard ICE within football clubs as the sum of human capital efficiency (HCE) and relational/structural capital efficiency (RSCE), as depicted in Figure 1.

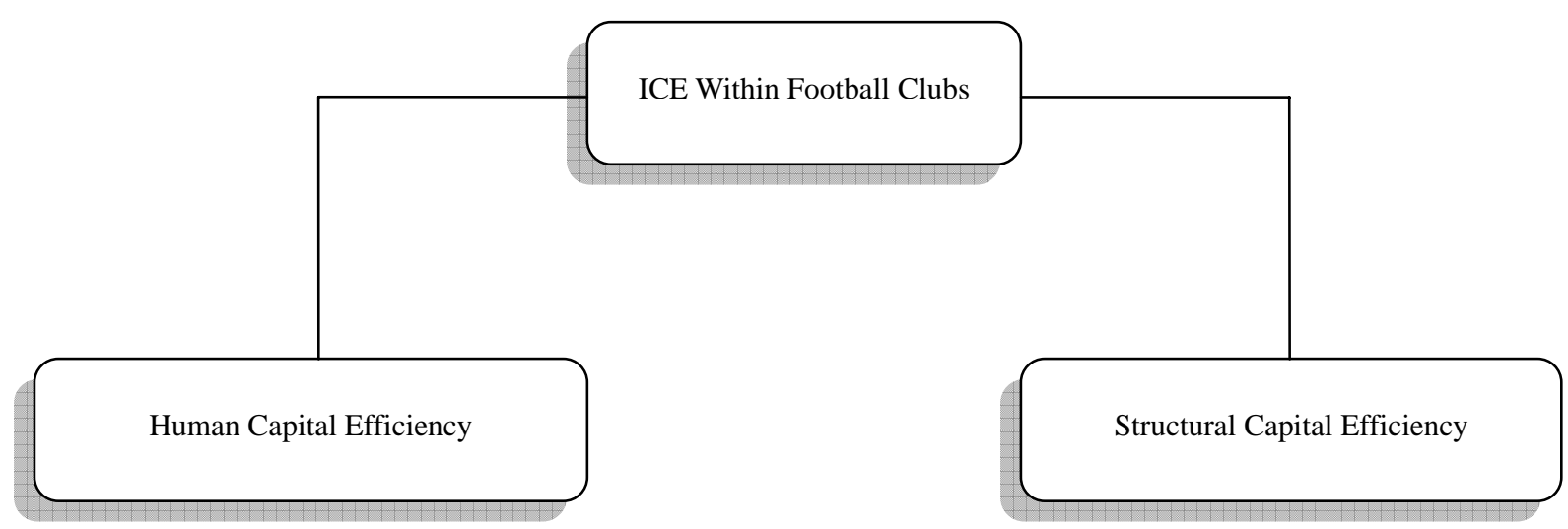

Figure 1. ICE within football clubs. 
While IC researchers mostly agree on this basic taxonomy, the issue of IC measurement is still at an "exploratory stage” (Nazari \& Herremans, 2007) due to a lacking consensus on a general measurement approach or coherent measurement theory for IC. Moreover, any discussion of IC measurement is inherently context-specific, because IC is to be considered as "something absolutely peculiar to each and every company", hence the selection of IC categories and measures needs to consider and be based on the "idiosyncratic situation" of each company (Bontis, Dragonetti, Jacobsen, \& Roos, 1999). In line with this argument, the need has been stressed to develop and use IC measures that are specifically relevant to the organization to which they relate (Shulver, Lawrie, \& Andersen, 2000).

\section{Independent Variables}

Considering all the above, this paper attempts to provide measures for ICE specifically tailored to professional football clubs. Based on accounting figures, we propose two indicators which are intended to measure distinct dimensions of IC ability for football clubs, namely, the HCE and RSCE. These indicators are essentially output-to-input ratios.

As far as the HCE is concerned, we focus on the players in squad as the main source of human capital. According to Rowbottom (2002), professional football players are quite distinct from other employees mainly because the players' registration rights are accounted as assets on the balance sheet. The rationale for this is that players' registrations get traded in the transfer market generating huge costs for the clubs which acquire them: "It is the existence of the measurement aspect in the form of the market place in which the registration of a player $(\ldots)$ is transferred between clubs, which distinguishes football players from other groups of employees” (Morrow, 1996, p. 82). Therefore, IC accounting, in terms of human capital, already exists in the football industry (Shareef \& Davey, 2005), albeit limited to accounting for purchased players.

Based on this accounting information, we propose an indicator having as numerator the revenues from players' trading (that arise when the selling price of players' registrations exceeds their book value) and the values of players' registration rights as denominator. The resulting efficiency ratio referred by the acronym HCE is defined as follows:

$$
H C E=\frac{\text { Revenues from players' trading }}{\text { Players' registration rights }}
$$

The rationale for this indicator lies in the assumption that football clubs are more or less efficient with respect to their human capital insofar as they manage to increase, through training and development activities, the value and "tradability" of their players' registration rights. Based on this assumption, we regard this ratio as measuring the ICE of football clubs as far as human capital is concerned.

As far as the RSCE is concerned, we propose a second ratio having as numerator the sum of different revenues streams accruing from key external stakeholders. Specifically, the external sources of revenues have been grouped as follows:

(1) Revenues from TV rights;

(2) Corporate image revenues, composed of merchandising, sponsorship, and advertising revenues;

(3) Match revenues.

All such sources of revenues taken together are assumed as forming revenues from the relational capital of football clubs, that is the ability to nurture and develop positive business relationships with key external 
stakeholders. It should be noted, however, that under the rubric "corporate image revenues", one might also include the brand value of football clubs, which should nevertheless be considered separately within the construct of structural capital. In this paper, however, the brand value is not considered as a separate entity and thus, the efficiency of relational and structural capital is measured at an aggregate level.

Specifically, the indicator for the efficiency of relational and structural capital is obtained by dividing the sum of revenues from customer capital (which intrinsically embody the brand value) by the difference between the value of total assets and the value of players' registration rights (as this latter has already been included in the first proposed indicator). The resulting indicator referred by the acronym RSCE (relational and structural capital efficiency) is as follows:

$$
R S C E=\frac{(\text { Revenues from } T V \text { rights }+ \text { Corporate image revenues }+ \text { Gate revenues })}{(\text { Total assets }- \text { Players ' registration rights })}
$$

\section{Study Population and Data Sources}

Our empirical investigation is based on a population of professional football clubs playing in the top-flight division (Serie A) of Italian football, observed over the time period from 2007 to 2012.

The data needed to construct the efficiency indicators have been drawn from the balance sheets, which are either freely available on clubs' websites (only for listed clubs) or accessible through the website of the Italian Business Register (Registro delle Imprese: http://www.registroimprese.it/), which provides access to the whole Chambers of Commerce information system.

Data on club performance (end-of-league points) have been drawn from the Official League Championship (Serie A) website (http://www.legaseria.it).

Table 1

Clubs Included in This Study

Club

Cagliari

Catania

Fiorentina

Genoa

Inter

Juventus

Lazio

Milan

Napoli

Palermo

Roma

Udinese

Total club-year observations $=60$

To provide a balanced data panel, we chose to include in this analysis only those clubs which have never been demoted from the top division in the time period being studied. Specifically, our population consists of 12 football clubs that have played in the "Serie A" from the 2007-2008 season up to the 2011-2012 season, with a total of 60 club-year observations. Table 1 above lists the clubs used in this study. 


\section{Data Analysis Method}

The analysis of data has been made using the statistical technique known as linear mixed-effects regression model, also known as hierarchical linear modelling, random coefficient modelling, and multilevel modelling.

Multilevel modelling is a flexible data analysis technique that involves analyzing linear models (e.g., the general linear model used in conjunction with ANOVA and regression) with a hierarchically nested structure. It is a more restrictive form of the mixed effects general linear model. In other words, multilevel modelling is an approach that handles data where observations are not independent but instead cluster by one or more grouping variables. The classic example is that of students, nested within classrooms, nested within schools, nested within school districts, etc.. Another frequently used application of multilevel modelling is the analysis of data collected on individuals over time (see, in particular, Goldstein, Healy, \& Rasbash, 1994). The latter type of data are interchangeably called longitudinal, repeated measures or panel data, and studies of the kind also carry a variety of labels, including repeated measures designs, longitudinal analysis, and growth models. In longitudinal data, the same response variable (e.g., club performance scores) is measured at different time points on each subject (football club); as a result, such data have a hierarchical structure with successive measurements nested within subjects.

Multilevel modelling deals more adequately than traditional regression methods with nested data, in that it drops the assumption of independence of observations, and allows the researcher to estimate both fixed and random effects on more than one level of a hierarchical structure simultaneously. Relationships are no longer assumed to be fixed over contexts (e.g., time, HCE), and therefore, they are allowed to differ. These models are more realistic than traditional regression models, due to making less restrictive assumptions. However, this generality has its counterpart. As a matter of fact, multilevel models are not computationally parsimonious, as more parameters are estimated, the outcomes may be more sample-specific, larger data sets are needed for stable solutions, and they use more complex estimation methods than the ordinary least squares method applied in traditional linear regression (comprehensive overviews of multilevel modelling that contain multiple examples and thorough appraisals are given in Bryk \& Raudenbush, 1992; Goldstein, 1995; Kreft \& De Leeuw, 1998). ${ }^{1}$

In this analysis, we discuss the so-called "two-level model”. The Level-1 model is a linear individual growth model, modelling the way in which each individual (here, each football club and its score achievement) changes over time. The Level-2 model expresses variation in the parameters from the growth model as random effects that occur between individuals (i.e., the change in individuals as a group over time). From a statistical point of view, this is an example of the conditional multilevel model, because these random effects are related to some club-level covariates, such as the HCE and the RSCE.

Typically, in a longitudinal analysis or growth modelling, we are not only interested in change over time. We are also interested in how growth may be influenced by background covariates (in this instance, the HCE and the RSCE). This type of model adds some complexity to the classic unconditional growth curve model (i.e., without contextual effects). In fact, as opposed to classic regression models, we have a more complex model that contains both fixed and random effects. The latter are typically incorporated in the intercept and the time-slope parameters of the regression model, as follows:

\footnotetext{
1 The interested readers should also consult the Centre for Multilevel Modelling at the University of Bristol for further information on multilevel models (centre website: http://www.bristol.ac.uk/cmm/).
} 


$$
y_{i j}=x_{i j}^{\prime} \beta+e_{i j}=\beta_{0}+\beta_{1} \times T I M E_{i j}+e_{i j}
$$

where:

$$
\begin{aligned}
& \beta_{0 i}=b_{0}+b_{1} \times H C E+b_{2} \times R S C E+v_{0 i} ; \\
& \beta_{1 i}=c_{0}+c_{1} \times H C E+c_{2} \times R S C E+v_{1 i} .
\end{aligned}
$$

From these relations, we have the multilevel model setting:

$$
\begin{gathered}
y_{i j}=b_{0}+b_{1} \times H C E_{i j}+b_{2} \times R S C E_{i j}+\left(c_{0}+c_{1} \times H C E_{i j}+c_{2} \times R S C E_{i j}+v_{1 i}\right) \times T I M E_{i j}+v_{0 i} \\
+e_{i j}=b_{0}+c_{0} \times T I M E_{i j}+b_{1} \times H C E_{i j}+b_{2} \times R S C E_{i j}+c_{1} \times H C E_{i j} \times T I M E_{i j}+ \\
c_{2} \times R S C E_{i j} \times T I M E_{i j}+v_{1 i} \times T I M E_{i j}+v_{0 i}+e_{i j}
\end{gathered}
$$

In the relations in Equations (3) and (4), the subscript $i j$ means that we deal with the $i$-th football club measured at the $j$-th time instant.

We propose, in this paper, a variance least squares (VLS) solution for the fixed and random effects estimates, due to the circumstance that we deal with the complete population set of clubs in the years considered. The VLS is a non-iterative distribution-free estimation method, which finds estimates by considering the minimization of a model covariance least squares-based solution from the empirical covariance matrix of the model.

The estimates highlight some features of the score growth model over time. The most relevant issue, from a statistical point of view, is the "contrast" between the coefficients for the $C \_H C E$ and $C \_R S C E$ covariates that capture the relationship between the covariates and the initial status (i.e., initial score achievement) on one hand and their interaction-by-time effects on the other hand. The interpretation and significance of this "finding" are discussed in detail throughout next sections.

\section{Empirical Results and Discussion}

By running the model, we have first obtained the so-called fixed-effects solution, shown in Table 2 . This provides the parameters of the general regression equation which models the way in which club scores change over time, adjusting for the impact of HCE and RSCE covariates. The resulting regression equation is as follows:

$$
\begin{gathered}
\text { RelSCORE }=0.5270-0.00329 \times \text { TIME }+0.05841 \times C_{-} H C E-0.01841 \times C_{-} R S C E \\
-0.01483 \times T I M E \times C_{-} H C E+0.003185 \times R S C E
\end{gathered}
$$

As discussed in Table 2, we have explored the impact of the covariates on both the intercept and time-slope parameters of the growth model.

Table 2

Solution for Fixed Effects

\begin{tabular}{lc}
\hline Effect & Estimate \\
\hline Intercept & 0.5270 \\
$T I M E$ & -0.00329 \\
$C \_H C E$ & 0.05841 \\
$C \_R S C E$ & -0.01841 \\
$T I M E \times C \_H C E$ & -0.01483 \\
TIME $\times$ C_RSCE & 0.003185 \\
\hline
\end{tabular}


Since we have centred the HCE and RSCE covariates at their grand means, the term for the intercept of 0.5270 is the average intercept (initial score achievement) across football clubs at average values of HCE and RSCE; while the term for TIME of -0.00329 is the average time-slope (rate of change) across clubs. Hence, the "average” football club began with a relative score of 0.5270 and saw it decrease by 0.00329 per sporting season (with adjustments for the impact of the covariates).

The key variables of interest in this analysis are the coefficients for the centred covariates and their interaction with time. The coefficient for C_HCE (0.05841) captures the relationship between the covariate and initial status. It tell us that higher levels of HCE ( $\left.C_{-} H C E\right)$ impact positively the grand intercept (by +0.05841$)$. More specifically, the value of $C \_H C E=0.05841$ indicates that football clubs that differ by one point with respect to this covariate have intercepts that differ by 0.05841 from the grand intercept, hence they start with a performance score that is relatively higher relative to the "average" football club.

By contrast, the coefficient for $C_{-} R S C E$ is negative (-0.01841), signalling that relatively higher levels of RSCE impact negatively the grand intercept in the general equation. In other words, clubs with higher levels of RSCE tend, on average, to have initial score achievements lower than the population mean (estimated by the grand intercept).

The coefficients for TIME $\times$ C_HCE and TIME $\times C_{-}$RSCE , which indicate the interaction-by-time effects of HCE and RSCE (respectively) on club scores, provide the most interesting findings from the study. In particular, we find that the mean effect of HCE on the time-slope of the general regression curve is -0.01483 . This means that an increased efficiency of HCE produces a "flattening" of the time-slope parameter; in other words, the negatively-signed coefficient for TIME $\times$ C_HCE indicates that the time-slope parameter (i.e., the rate of change in club score) is lower in clubs with higher values of HCE. A possible explanation for this is that many clubs do not necessarily compete with the realistic expectation to win the championship or to rank in the first few top positions; and hence their choices in terms of best player retention and players' trading policies do not necessarily seem consistent with the objective of win maximization. In fact, as Baroncelli and Lago (2006) pointed out, club objectives within the Serie A championship are quite different for leading-edge clubs on one hand and small- and medium-sized clubs on the other hand. If for leading clubs sporting results can be expressed in terms of maximizing victories or higher-ranking (in the national championship as well as in European Leagues) sporting results of small- and medium-sized clubs can be more realistically expressed in terms of their having managed to remain in Serie A. Following the same line of reasoning, the business model of non-leading clubs appears to rely more heavily on the trading of talented players than leading clubs since they face tighter budget constraints in pursuing their sporting objectives. As a result, non-leading clubs may be efficient in managing their human capital, e.g., through the scouting and selection of young players who can be bought from minor divisions around the world, through putting together a team with a skilled trainer and then developing the talent and "tradability" of these players, but this ICE does not necessarily or not consistently translates into a superior growth of performance scores over time, since these clubs are often "forced" to sell the most talented players in the transfer market as a way to keep their profit and loss account healthy. It should be noted, however, that also leading clubs often find it convenient to sell their top players to cover losses and as a result, they too do not consistently achieve high sporting results over time (let alone the unpredictability of the game). 
By contrast, the interaction-by-time effect of RSCE on the grand slope is positively-signed $(+0.003185)$. This means that, on average, an increased efficiency of relational and structural capital produces an increase in the time-slope parameters. Put differently, the coefficient for TIME $\times$ C_RSCE (+0.003185) indicates that, on average, clubs characterized as having higher levels of RSCE have higher time-slope parameters, that is, the growth rate of their performance scores differs by +0.003185 (per each unitary increase in RSCE) from the average growth rate. This is arguably due to the fact that those which exhibit higher revenues from relational and structural capital are capable of exploiting wider commercial opportunities by capitalising on their brand names or customer loyalty (e.g., through relationship marketing initiatives, brand internationalization, investments in new means of communication). In turn, higher revenues from customer and structural capital augment the spending power of clubs in playing talent, which might explain our finding that relational capital efficiency impacts positively sporting performance over time.

Table 3 presents the club-specific random effects estimates.

Table 3

Solutions for Random Effects

\begin{tabular}{lcc}
\hline \multirow{2}{*}{ Club } & \multicolumn{2}{c}{ Effect } \\
\cline { 2 - 3 } & Intercept & Time \\
\hline Cagliari & -0.1445 & 0.01408 \\
Catania & -0.1500 & 0.01221 \\
Fiorentina & 0.04990 & -0.01999 \\
Genoa & -0.03966 & -0.00409 \\
Inter & 0.2277 & -0.03216 \\
Juventus & 0.07543 & -0.00003 \\
Lazio & -0.09643 & 0.01914 \\
Milan & 0.06953 & 0.009160 \\
Napoli & -0.04357 & 0.01249 \\
Palermo & -0.04123 & 0.000276 \\
Roma & 0.1483 & -0.02433 \\
Udinese & -0.05551 & 0.01324 \\
\hline
\end{tabular}

The random-effects estimates represent the estimated deviation from the overall intercept and time-slope parameters for each football club. So, for instance, the intercept for Cagliari F.C. is lower by 0.1445 than the overall intercept (0.52), while its time-slope parameter is higher by 0.01408 than the overall time-slope $(-0.0329)$.

Finally, Table 4 shows the so-called covariance estimated parameters.

Table 4

Covariance Estimated Parameters

\begin{tabular}{llc}
\hline Covariance parameter & Subject & Estimate \\
\hline UN $(1,1)$ & Club & 0.01928 \\
UN $(2,1)$ & Club & -0.00286 \\
UN $(2,2)$ & Club & 0.000643 \\
AR $(1)$ & Club & 0.2471 \\
Residual & & 0.006584 \\
\hline
\end{tabular}

Note. UN = Unstructured covariance structure; AR = Autoregressive model. 
Basically, the covariance parameters estimates tell us how much intercepts and time-slopes vary across clubs. So, 0.01928 tells us about the variability in intercepts, 0.000643 tells us about the variability in slopes, and -0.00286 tells us about the covariance between intercepts and slopes. The latter indicates a negative relationship between intercepts and slopes: those regression lines with lower intercepts tend to have higher slopes. Therefore, those clubs with a relatively low initial score tend to have relatively high score growth rates. Finally, the autoregressive parameter AR (1) indicates that there is a poor correlation between club performances from one season to the next.

\section{Research Summary, Limitations, and Further Perspectives}

In the last few decades, much has been written and debated on the strategic role of intangible or intellectual capital and a general agreement has been reached that intangible assets are primary drivers of sustainable competitive advantage and superior firm performance. Relatedly, management theory has come to acknowledge the need to manage effectively the intangible capital a company possesses as well as to measure its intellectual ability in order to provide managers with appropriate tools to control and handle these strategic assets.

Noticeably, a growing body of research has accumulated exploring the impact of corporate intellectual ability on firm performance. However, to the best of our knowledge, there are only two research articles testing the association of ICE with the measures of performance in the professional football industry. This paper was aimed to help fill this gap by empirically investigating the relationship between specific dimensions of ICE and club performance in the Italian professional football sector. Specifically, we aimed to assess the hypotheses that: (1) HCE had a positive impact on sporting performance (taken as a proxy for business performance); and

(2) RSCE had a positive impact on sporting performance. Our empirical investigation has provided mixed support for these predictions.

As far as the first hypothesis is concerned, we have shown on one hand the HCE of our football clubs to be positively associated with their initial score achievements, and on the other hand, we have found a negative association over time between HCE and the growth rate of club performance scores. As already noted, this finding might be explained by the fact that football clubs often trade away their best talented players as a way to keep their profit and loss account healthy, thus prioritizing economic objectives over sporting achievements.

As far as the second hypothesis is concerned, it has been found that a relatively higher level of RSCE was initially associated with lower performance scores; while over time, the rate of change of performance scores in clubs with a higher RSCE was relatively higher than the population average. A likely explanation for this is that some clubs are more efficient than others in building, nurturing, and turning their relational and structural capital into (additional) revenues, which in turn augment their spending power in players' talent and their sporting competitiveness; on the other hand, it should be noted that the business relationships with external stakeholders that underlie the various sources of commercial revenues take time to develop and therefore, they yield returns in both economic and sporting terms only in the medium-to-long term.

It is no doubt that our findings and conclusions suffer from many limitations that could, at least to some extent, be overcome through further research. The basic limitation of this study is that it is restricted to the first-tier Italian league (Serie A) and spans a relatively short period of time. Accordingly, future research directions should include extending the time-span of the analysis as well as replicating this study in lower-tier professional leagues of Italian football and possibly in other professional football leagues in Europe. Finally, future research should focus on identifying further measures of ICE for football clubs in order to capture the multidimensional aspect of the IC construct and generate more valuable conclusions about its impact on club performance. 


\section{References}

Alipour, M. (2012). The effect of intellectual capital on firm performance: An investigation of Iran insurance companies. Measuring Business Excellence, 16(1), 53-66.

Andrikopoulos, A., \& Kaimenakis, N. (2009). Introducing FOrNeX: A composite index for the intangible resources of the football club. International Journal of Sport Management and Marketing, 5(3), 251-266.

Appuhami, B. A. R. (2007). The impact of intellectual capital on investors' capital gains on shares: An empirical investigation of Thai banking, finance \& insurance sectors. International Management Review, 3(2), 14-25.

Barajas, A., Fernández-Jardón, C., \& Crolley, L. (2005). Does sports performance influence revenues and economic results in Spanish football? Retrieved from http://mpra.ub.uni-muenchen.de/3234/

Barney, J. B. (1991). Firm resources and sustained competitive advantage. Journal of Management, 17(1), 99-120.

Baroncelli, A., \& Lago, U. (2006). Italian football. Journal of Sports Economics, 7(1), 13-28.

Bassi, L. J., \& Van Buren, M. E. (1999). Sharpening the leading edge. Training and Development, 53(1), 23-33.

Bontis, N. (1998). Intellectual capital: An exploratory study that develops measures and models. Management Decision, 36(2), 63-76.

Bontis, N. (2001). Assessing knowledge assets: A review of the models used to measure intellectual capital. International Journal of Management Reviews, 3(1), 41-60.

Bontis, N., Dragonetti, N. C., Jacobsen, K., \& Roos, G. (1999). The knowledge toolbox: A review of the tools available to measure and manage intangible resources. European Management Journal, 17(4), 391-402.

Bontis, N., Keow, W. C., \& Richardson, S. (2000). Intellectual capital and business performance in Malaysian industries. Journal of Intellectual Capital, 1(1), 85-100.

Brooking, A. (1996). Intellectual capital: Core assets for the third millennium enterprise. London: International Thompson Business Press.

Bryk, A. S., \& Raudenbush, S. W. (1992). Hierarchical linear models: Applications and data analysis methods. Newbury Park, CA: Sage Publications.

Burton-Jones, A., \& Spender, J. C. (2011). The Oxford handbook of human capital. Oxford: Oxford University Press.

Cabrita, M., \& Vaz, J. (2006). Intellectual capital and value creation: Evidence from the Portuguese banking industry. The Electronic Journal of Knowledge Management, 4(1), 11-20.

Chan, K. H. (2009). Impact of intellectual capital on organisational performance: An empirical study of companies in the Hang Seng Index (Part 2). The Learning Organization, 16(1), 22-39.

Chen, M. C., Cheng, S. J., \& Hwang, Y. (2005). An empirical investigation of the relationship between intellectual capital and firms' market value and financial performance. Journal of Intellectual Capital, 6(2), 159-176.

Dawson, P., Dobson, S., \& Gerrard, B. (2000). Estimating coaching efficiency in professional team sports: Evidence from English association football. Scottish Journal of Political Economy, 47(4), 399-421.

Deloitte \& Touche. (1999). Informe Anual 1996/97 sobre las Finanzasen la Primera División del Fútbolen España. Deloitte \& Touche.

Deloitte \& Touche. (2000a). Annual review of football finance: A review of the 1998/1999 season. Deloitte \& Touche.

Deloitte \& Touche. (2000b). Informe Anual 1997/98 y 1998/99. Las Finanzasen la Primera División del Fútbolen España. Deloitte \& Touche.

Dimitropoulos, P. E., \& Koumanakos, E. (2015). Intellectual capital and profitability in European football clubs. International Journal of Accounting, Auditing, and Performance Evaluation, 11(2), 202-220.

Edvinsson, L. (1997). Developing intellectual capital at Skandia. Long Range Planning, 30(3), 366-373.

Edvinsson, L. (2000). Some perspectives on intangibles and intellectual capital. Journal of Intellectual Capital, 1(1), 12-16.

Edvinsson, L., \& Malone, M. S. (1997). Intellectual capital: The proven way to establish your company's real value by measuring its hidden brainpower. New York, NY: Harper Business.

El-Hodiri, M., \& Quirk, J. (1971). An economic model of a professional sports league. The Journal of Political Economy, 79(6), 1302-1319.

Firer, S., \& Stainbank, L. (2003). Testing the relationship between intellectual capital and a company's performance: Evidence from South Africa. Meditari Accountancy Research, 11(1), 25-44.

Goldstein, H. (1995). Multilevel statistical models. London: Edward Arnold. 
Goldstein, H., Healy, M. J. R., \& Rasbash, J. (1994). Multilevel time series models with applications to repeated measures data. Statistics in Medicine, 13(16), 1643-1655.

Hall, R. (1992). The strategic analysis of intangible resources. Strategic Management Journal, 13(2), 135-144.

Hall, R. (1993). A framework linking intangible resources and capabilities to sustainable competitive advantage. Strategic Management Journal, 14(8), 607-618.

Hitt, M. A., Bierman, L., Shimizu, K., \& Kocchar, R. (2001). Direct and moderating effects of human capital on strategy and performance in professional service firms: A resource-based perspective. Academy of Management Journal, 44(1), 13-28.

Hoehn, T., \& Szymanski, S. (1999). The Americanization of European football. Economic Policy, 14(28), $204-240$.

Itami, H. (1987). Mobilizing invisible assets. Boston: Harvard University Press.

Itami, H., \& Roehl, T. W. (1987). Mobilizing invisible assets. Cambridge, MA: Harvard University Press.

Kreft, I., \& De Leeuw, J. (1998). Introducing multilevel modeling. Thousand Oaks, CA: Sage Publications.

Maditinos, D., Chatzoudes, D., Tsairidis, C., \& Theriou, G. (2011). The impact of intellectual capital on firms' market value and financial performance. Journal of Intellectual Capital, 12(1), 132-151.

Marr, B., \& Roos, G. (2005). A strategy perspective on intellectual capital. In B. Marr (Ed.), Perspectives on intellectual capital: Multidisciplinary insights into management, measurement, and reporting. Oxford: Butterworth-Heinemann.

McGaughey, S. L. (2002). Strategic interventions in intellectual asset flows. Academy of Management Review, 27(2), $248-274$.

Mnzava, B. (2013). Do intangible investments matter? Evidence from soccer corporations. Sport, Business, and Management: An International Journal, 3(2), 158-168.

Morrow, S. (1996). Football players as human assets. Measurement as the critical factor in asset recognition: A case study investigation. Journal of Human Resource Costing and Accounting, 1(1), 75-97.

Nahapiet, J., \& Ghoshal, S. (1998). Social capital, intellectual capital, and the organizational advantage. Academy of Management Review, 23(2), 242-266.

Nazari, J. A., \& Herremans, I. M. (2007). Extended VAIC model: Measuring intellectual capital components. Journal of Intellectual Capital, 8(4), 595-609.

Pulic, A. (2000). MVA and VAIC analysis of randomly selected companies from FTSE 250. Retrieved from http://www.vaic-on.net/start.htm

Pulic, A. (2008). The principles of intellectual capital efficiency: A brief description. Zagreb: Croatian Intellectual Capital Center. Retrieved from http://www.cik-hr.com/data/principles_2008.pdf

Riahi-Belkaoui, A. (2003). Intellectual capital and firm performance of US multinational firms: A study of the resource-based and stakeholder views. Journal of Intellectual Capital, 4(2), 215-226.

Roos, G., \& Roos, J. (1997). Measuring your company’s intellectual performance. Long Range Planning, 30(3), 413-426.

Rowbottom, N. (2002). The application of intangible asset accounting and discretionary policy choices in the UK football industry. British Accounting Review, 34(4), 335-355.

Schiuma, G., Lerro, A., \& Sanitate, D. (2008). The intellectual capital dimensions of Ducati’s turnaround: Exploring knowledge assets grounding a change management program. International Journal of Innovation Management, 12(2), 161-193.

Schultz, T. W. (1961). Investment in human capital. The American Economic Review, 51(1), 1-17.

Sharabati, A. A., Jawad, S. N., \& Bontis, N. (2010). Intellectual capital and business performance in the pharmaceutical sector of Jordan. Management Decision, 48(1), 105-131.

Shareef, F., \& Davey, H. (2005). Accounting for intellectual capital: Evidence from listed English football clubs. Journal of Applied Accounting Research, 7(3), 78-116.

Shiu, H. J. (2006). The application of the value added intellectual coefficient to measure corporate performance: Evidence from technological firms. International Journal of Management, 23(2), 356-365.

Shulver, M., Lawrie, G., \& Andersen, H. (2000). A process for developing strategically relevant measures of intellectual capital. Proceedings of the 2nd International Conference on Performance Measurement, Cambridge, UK. Retrieved from http://213.155.109.122/esgp/files/sources/30_20111215034051325.pdf

Smith, A. (1776). An inquiry into the nature and causes of the wealth of nations. London: W. Strahan and T. Cadell.

Spender, J. C., \& Grant, R. M. (1996). Knowledge and the firm: Overview. Strategic Management Journal, 17(S2), 5-9.

Stewart, T. A. (1997). Intellectual capital: The new wealth of organizations. New York, NY: Doubleday.

Sveiby, K. E. (1998). Intellectual capital and knowledge management. Retrieved from http://www.sveiby.com/articles/IntellectualCapital.html

Szymanski, S., \& Kuypers, T. (1999). Winners and losers: The business strategy of football. London: Viking. 
Szymanski, S., \& Smith, R. (1997). The English football industry: Profit, performance, and industrial structure. International Review of Applied Economics, 11(1), 135-153.

Teece, D. J. (2000). Managing intellectual capital: Organizational, strategic, and policy dimensions. Oxford: Oxford University Press.

Youndt, M. A., Subramaniam, M., \& Snell, S. A. (2004). Intellectual capital profiles: An examination of investments and returns. Journal of Management Studies, 41(2), 335-361.

Zeglat, D., \& Zigan, K. (2014). Intellectual capital and its impact on business performance: Evidences from the Jordanian hotel industry. Tourism and Hospitality Research, 13(2), 83-100. 